\title{
In vitro Neurogenesis by Neuronal Precursor Cells Derived from the Adult Songbird Brain
}

\author{
Steven A. Goldman, ${ }^{1}$ Anita Zaremba, ${ }^{1}$ and Donna Niedzwiecki ${ }^{2}$ \\ 'Department of Neurology and Neuroscience, Cornell University Medical College, and 'Division of Biostatistics, Memorial \\ Sloan-Kettcring Cancer Center, New York, New York 10021
}

\begin{abstract}
The vocal control nucleus of the adult songbird forebrain, HVc, exhibits de novo neurogenesis in adulthood, with the production of new neurons from precursor cells located in the overlying ventricular zone (Goldman and Nottebohm, 1983). We previously established that explants derived from neurogenic regions of the adult canary forebrain could be maintained in vitro, under conditions that permitted the migration and differentiation of those new neurons previously generated in vivo (Goldman, 1990). However, we found no evidence for continued neuronal mitogenesis in these cultures, which were raised in high concentrations of serum.

In the present study, we investigated the permissive conditions for in vitro neurogenesis by these adult forebrainderived ventricular zone explants. When HVc explants derived from adult zebra finches were maintained in low-serum medium, in vitro neurogenesis could be demonstrated by ${ }^{3} \mathrm{H}-$ thymidine uptake as long as $\mathbf{5}$ days after explantation. Immunocytochemistry for microtubule-associated protein-2 followed by autoradiography confirmed the neuronal identity of these ${ }^{3} \mathrm{H}$-thymidine-incorporating cells. In vitro neuronal production occurred in an inverse relation to the serum concentration: Over the range of $2.5-25 \%$ fetal bovine serum, neuronal ${ }^{3} \mathrm{H}$-thymidine labeling was most frequent in those cultures exposed to the lowest serum levels. This facilitation of in vitro neuronal mitogenesis by serum depletion suggests that fetal serum may contain factors that inhibit the division of adult-derived neuronal precursor cells, either directly or by agents released by serum-stimulated glial or ependymal cells.
\end{abstract}

The vocal control nucleus of the adult songbird forebrain, $\mathrm{HVc}$ (hyperstriatum ventralis, pars caudale), exhibits de novo neurogencsis in adulthood, with the production of new neurons from precursor cells located in the overlying ventricular zone (Goldman and Nottebohm, 1982, 1983). Precursor cell mitosis is followed by the directed migration of the daughter cells into the underlying $\mathrm{HVc}$, where they differentiate into neurons (Goldman, 1983; Goldman and Nottebohm, 1983; AlvarezBuyulla and Nottebohm, 1988), and become functionally inte-

\footnotetext{
Received Aug. 16, 1991; revised Jan. 22, 1992; accepted Jan. 28, 1992.

We thank Drs. Fred Plum, Maiken Nedergaard, and William Pulsinelli for their comments on the manuscript. This work has been supported by grants from the G. Harold and Leila Y. Mathers Foundation, and by NINDS Grant NS-01316 to S.A.G., who is a Cornell Scholar in Biomedical Science.

Correspondence should be addressed to Stephen Goldman, M.D., Ph.D., Department of Neurology, Room E607, Cornell University Medical College, 1300 York Avenue, New York, NY 10021.

Copyright (C) 1992 Society for Neuroscience $0270-6474 / 92 / 122532-10 \$ 05.00 / 0$
}

grated into the existing neural network (Paton and Nottebohm, 1984). We previously established that ventricular zone explants derived from the adult canary HVc (Serinus canarius) could be maintained in vitro, under conditions in which the ongoing migration and differentiation of newly generated neurons proceeded in robust fashion (Goldman and Clarke, 1989; Goldman, 1990). Using ${ }^{3} \mathrm{H}$-thymidine autoradiography and immunocytochemistry for ncuron-specific antigens, it was demonstrated that the cellular outgrowth arising from these explants included new neurons, which had been generated in vivo in the few days prior to explantation. However, although these newborn cells matured into neurons in vitro, they did so postmitotically: we found no evidence for neuronal production from precursor mitogenesis in these cultures (Goldman, 1990).

A similar cessation of in vitro neuronal production by cells known to be continuously mitotic in vivo has been described in other neurogenic systems (e.g., Calof and Chikaraishi, 1989). Several authors have described transient neurogenesis in mixed cultures of embryonic rodent neuroectoderm (e.g., Sensenbrenner et al., 1980; Federoff et al., 1982; Kriegstein and Dichter, 1984). Among late-embryonic neuronal precursors, terminal division has been observed in cultures of embryonic day 17 (E17) hippocampus (Banker and Cowan, 1977; Mattson et al., 1989), in the absence of sustained in vitro neurogenesis. Neuronal precursors derived from early embryonic neuroepithelium, in contrast, have been shown to retain more long-lasting capabilities for neuronal mitogenesis in culture: Barakat et al. $(1983,1984)$ have reported in vitro neurogenesis by precursor cells derived from embryonic chick forebrain (E6), and have further demonstrated the serum-dependent inhibition of neuroblastic mitosis. More recently, persistent in vitro neurogenesis has been observed among fetal neuroepithelial precursors raised in the presence of both basic fibroblast growth factor (bFGF) (Gensburger et al., 1987; Murphy et al., 1990) and bFGF with NGF (Cattaneo and McKay, 1990), as well as in single cell striatal microcultures (Temple, 1989), and in postnatal cerebellar granule cell cultures (Gao and Hatten, 1990). Furthermore, Ronnett et al. (1990) have reported the continuous in vitro proliferation of neural cells derived from postnatal human megalencephalic brain, although the transformation state of these cells is unclear. Among adult central nervous tissues, however, only in teleost fish has sustained neurogenesis been achieved in vitro; specifically, neuronal production has been obtained in cultures derived from the neurogenic ependyma of the adult Stenarchus spinal cord (Anderson and Waxman, 1985).

Intrigued by the apparent cessation of ventricular zone neurogenesis in cultures derived from the adult avian forebrain, we postulated that the fetal serum of our culture media might har- 
bor factors that are antimitogenic for these precursor cells, either directly so or by promoting their terminal neuronal differentiation. This hypothesis predicted that in vitro neuronal production by neurogenic ventricular epithelium would be achievable in a low-serum medium, that is, a formulation relatively free of potential antimitotic and prodifferentiation factors. We tested this prediction using forebrain explant cultures derived from the adult zebra finch (Poephilia guttata), an oscine songbird related to the canary. Using in vitro ${ }^{3} \mathrm{H}$-thymidine exposure and autoradiography, we found that $\mathrm{HVc}$ ventricular zone cultures exhibited neuronal ${ }^{3} \mathrm{H}$-thymidine incorporation, and inferentially neuronal precursor mitosis, for up to $5 \mathrm{~d}$ in vitro (5 DIV), and that this process was encouraged by relative serum depletion.

A preliminary report of this work has been published in abstract form (Goldman and Zaremba, 1991).

\section{Materials and Methods}

Adult forebrain culture preparation. Ventricular zone explant cultures derived from the adult zebra finch, Poephilia guttata, were prepared as previously described in the canary, Serinus canarius (Goldman, 1990), with minor modifications: 1-year-old female finches were obtained from Supreme Exotic Birds (Mount Vernon, NY) and housed in group flight cages for at least 1 month in our facility before use. The light cycle was naturally varying, and light was provided using Vita-Lite natural-spectrum artificial illumination. Experimental birds were anesthetized with pentobarbital $(0.6 \mathrm{mg}$ in $0.18 \mathrm{ml}$ of saline, i.m. ) and perfused transcardially with phenol red-free sterile Hank's balanced salt solution (HBSS) at $25^{\circ} \mathrm{C}$. The ventricular zones overlying the HVc and its adjacent dorsomediocaudal neostriatum were bilaterally dissected out into warm tissue culture media. Approximately 60 explants, each roughly $0.8 \times$ $0.5 \times 0.2 \mathrm{~mm}$, were obtained from each bird, and distributed in groups of six into $35 \mathrm{~mm}$ Falcon Primaria dishes previously coated with mouse laminin. The surfaces of these plates had been coated [20 $\mu \mathrm{g}$ of murine laminin/dish; GIBCO and Collaborative Research] to a maximal surface deposition of $2.1 \mu \mathrm{g} / \mathrm{cm}^{2}$. Six hundred fifty microliters of culture medium were added to each dish, and the prepared cultures were incubated at $37^{\circ} \mathrm{C}$ in a humidified, $5 \% \mathrm{CO}_{2}, 95 \%$ air environment. ${ }^{3} \mathrm{H}$-thymidine was added at various time points following explantation, as described below. All plates were incubated for $5 \mathrm{~d}$ before daily observations were begun, with bidaily neuronal cell counts. Each culture was supplemented with $100 \mu \mathrm{l}$ of fresh media on the fourth and seventh days in vitro, and partial media exchanges of $250 \mu \mathrm{l}$ were done every third day thereafter.

Media composition. In order to test the hypothesis that in vitro neurogenesis is constrained by serum-borne factors, we first needed to maintain adult forebrain explants in low-serum culture. Our base medium was a modification of the serum-free and low-serum medium formulations of Bottenstein and Sato (1979) and Lillien et al. (1988), respectively. A 1:1 mix of Dulbccco's modificd Eaglc's medium : Ham's F-12, made up free of phenol red and glutamate, was supplemented with 15 mM HEPES buffer, $2 \mathrm{~mm}$ L-glutamine, $100 \mu \mathrm{m}$ nonessential amino acids, $5 \mu \mathrm{g} / \mathrm{ml}$ insulin, $6 \mathrm{mg} / \mathrm{ml}$ D-glucose, $16 \mu \mathrm{g} / \mathrm{ml}$ putrescine, $60 \mathrm{fg} / \mathrm{ml}$ progesterone, $40 \mathrm{ng} / \mathrm{ml}$ selenium, $30 \mathrm{ng} / \mathrm{ml}$ triiodothyronine, $100 \mu \mathrm{g} / \mathrm{ml}$ transferrin, $100 \mu \mathrm{g} / \mathrm{ml}$ bovine serum albumin, $40 \mathrm{U} / \mathrm{ml}$ penicillin, and $40 \mathrm{U} / \mathrm{ml}$ streptomycin. (All components except serum were obtained from GIBCO/BRL or Collaborative Research.) Incremental amounts of charcoal-pretreated fetal bovine sera (see below) were then added to aliquots of the base media, in order to provide a set of media containing serum concentrations of $25 \%, 10 \%, 5 \%, 2.5 \%, 1.25 \%$, and $0.625 \%$.

Charcoal pretreatment of serum. The fetal bovine sera (FBS) used in this study (Cocalico Biologicals) was charcoal pretreated (denoted here as C-FBS) for the removal of steroids and low molecular weight proteins. Although testosterone and estradiol have no discernible cffect upon neuronal production in adult canaries in vivo (S. A. Goldman and A. Hidalgo, unpublished observations), their mitogenic effects upon canary HVc glial and endothelial cells are significant (Goldman, 1983; Goldman and Nottebohm, 1983); these proliferating support cells might in turn influence the cell cycle kinetics of the neuronal precursor pool. Estradiol and testosterone levels were undetectable in both serum and final media, as assayed by commercial radioimmunoassay (RIA) to sensitivities of 10 and $100 \mathrm{pg} / \mathrm{ml}$, respectively (estrogen RIA: Mayo Clinic Laboratories; testosterone: SmithKline and Mayo).

${ }^{3} \mathrm{H}$-thymidine exposure. A total of 1231 ventricular zone explants derived from the adult zebra finch $\mathrm{HVc}$ and dorsomediocaudal neostriatum were distributed among the six media formulations. At various time points, including $24,48,72,96$, and $120 \mathrm{hr}$ after explantation, ${ }^{3} \mathrm{H}-$ thymidine $(0.2 \mu \mathrm{Ci} / 20 \mu$ l HBSS $)$ was added to every plate. These time points will be denoted in the text as $1,2,3,4$, and $5 \mathrm{~d}$, respectively. ${ }^{3} \mathrm{H}$-thymidine was obtained as an aqueous solution from New England Nuclear/Du Pont (NET-027) and had a specific activity of $6.7 \mathrm{Ci} / \mathrm{mm}$. The explants were raised for $7 \mathrm{~d}$ following ${ }^{3} \mathrm{H}$-thymidine addition, after which they were fixed for $20 \mathrm{~min}$ in cold $4 \%$ paraformaldehyde, prior to immunostaining and autoradiography as described below.

Combined autoradiography/immunocytochemistry. Neurons were identified immunocytochemically in explant outgrowths prior to autoradiography, so as to allow single cell determinations of neuronal ${ }^{3} \mathrm{H}$ thymidine incorporation. A monoclonal antibody directed against $\mathrm{mi}-$ crotubule-associated protein-2 (MAP-2) was used for this purpose, due to the neuron-selective localization of this antigen (Bernhardt and Matus, 1985; Caceres et al., 1986; Fisher et al., 1987), which we characterized previously in these cultures (Goldman, 1990). Explant cultures were raised in ${ }^{3} \mathrm{H}$-thymidine as noted and, after fixation in $4 \%$ paraformaldehyde in PBS, were immunostained using mouse anti-MAP-2 IgG ( $1: 200$; clone HM-2, Sigma). Immunoperoxidase localization of MAP-2 was employed using avidin-biotin amplification (Vector Laboratories), and the chromogenic substrate aminoethyl carbazole. Immunostaining methods were otherwise as previously described (Goldman, 1990). These MAP-2-stained culture outgrowths were air dried and dipped into NTB-3 emulsion (Kodak), incubated for $3 \mathrm{~d}$ at $4^{\circ} \mathrm{C}$, and then developed using Kodak D-19 $\left(3 \mathrm{~min}\right.$ at $16^{\circ} \mathrm{C}$, with $1 \mathrm{~min}$ in stop solution and $12 \mathrm{~min}$ in Kodak fixer). The autoradiographed cultures were then covered with glycerol:PBS (3:1), and examined by phase and Nomarski optics using an Olympus IMT2 inverted photomicroscope.

Methodological controls. As a control for unscheduled DNA synthesis in this ${ }^{3} \mathrm{H}$-thymidine-containing media, 71 ventricular zone explants, identically derived from the adult zebra finch $\mathrm{HVc}$ and its adjacent neostriatum, were exposed to ${ }^{3} \mathrm{H}$-thymidine after $7 \mathrm{DIV}$, fixed $1 \mathrm{~d}$ later, and subsequently autoradiographed. Twenty-eight of these explants were raised in 5\% charcoal-pretreated FBS (C-FBS), and 43 in 25\% C-FBS. The relatively short period of time between isotope addition and fixation was intended to preclude substantial morphological development by any ${ }^{3} \mathrm{H}$-thymidine-incorporating cells. This allowed us to estimate the the occurrence, if any, of unscheduled ${ }^{3} \mathrm{H}$-thymidine incorporation by mature postmitotic neurons in these cultures.

Distribution of cultures among test conditions. A total of 27 adult female zebra finches were used in this study; all were at least 1 year old. These included 23 experimental birds, and 4 additional finches who provided explants for the methodological controls noted above. Approximately $60 \mathrm{HVc}$ and mediocaudal neostriatal ventricular zone explants were obtained from each bird, pooled, and randomly distributed among an average of 10 culture plates per finch. These cultures were next randomized to one of four media formulations $(25 \%, 10 \%, 5 \%$, or $2.5 \%$ C-FBS). Cultures derived from two of the experimental birds were also raised in cither $0.625 \%$ or $1.25 \% \mathrm{C}$-FBS. ${ }^{3} \mathrm{H}$-thymidine was then added to each plate at one of the following time points after explantation: $1,2,3,4$, or $5 \mathrm{~d}$ in vitro. Each experimental group was thus defined by a unique combination of serum concentration and time point of ${ }^{3} \mathrm{H}$ thymidine addition. Occasional losses of cultures due to explant detachment, contamination, or technical failures in autoradiography or immunochemistry resulted in an unequal number of explants in each group.

The neuronal labeling index. The outcome measure of interest was the percentage of neurons arising from each explant that were labeled with ${ }^{3} \mathrm{H}$-thymidine. This value, the neuronal labeling index (LI), was defined as the number of ${ }^{3} \mathrm{H}$-thymidine-labeled, MAP-2-positive neurons, divided by the total number of neurons found in that explant's cellular outgrowth, expressed as a percentage. ${ }^{3} \mathrm{H}$-thymidine-labeled cells were defined as those with 10 or morc silver grains over their nuclei. Background grain deposition was low in this preparation, averaging less than $1 \mathrm{grain} / 10^{2} \mu \mathrm{m}^{2}$, so that labeling was rarely ambiguous. All raw cell counts, cell type determinations, and autoradiographic labeling assessments were performed by a single observer who had no foreknowledge of the serum level or ${ }^{3} \mathrm{H}$-thymidine exposure conditions to which each culture was subjected.

Statistical analysis. Several factors were considered for possible as- 

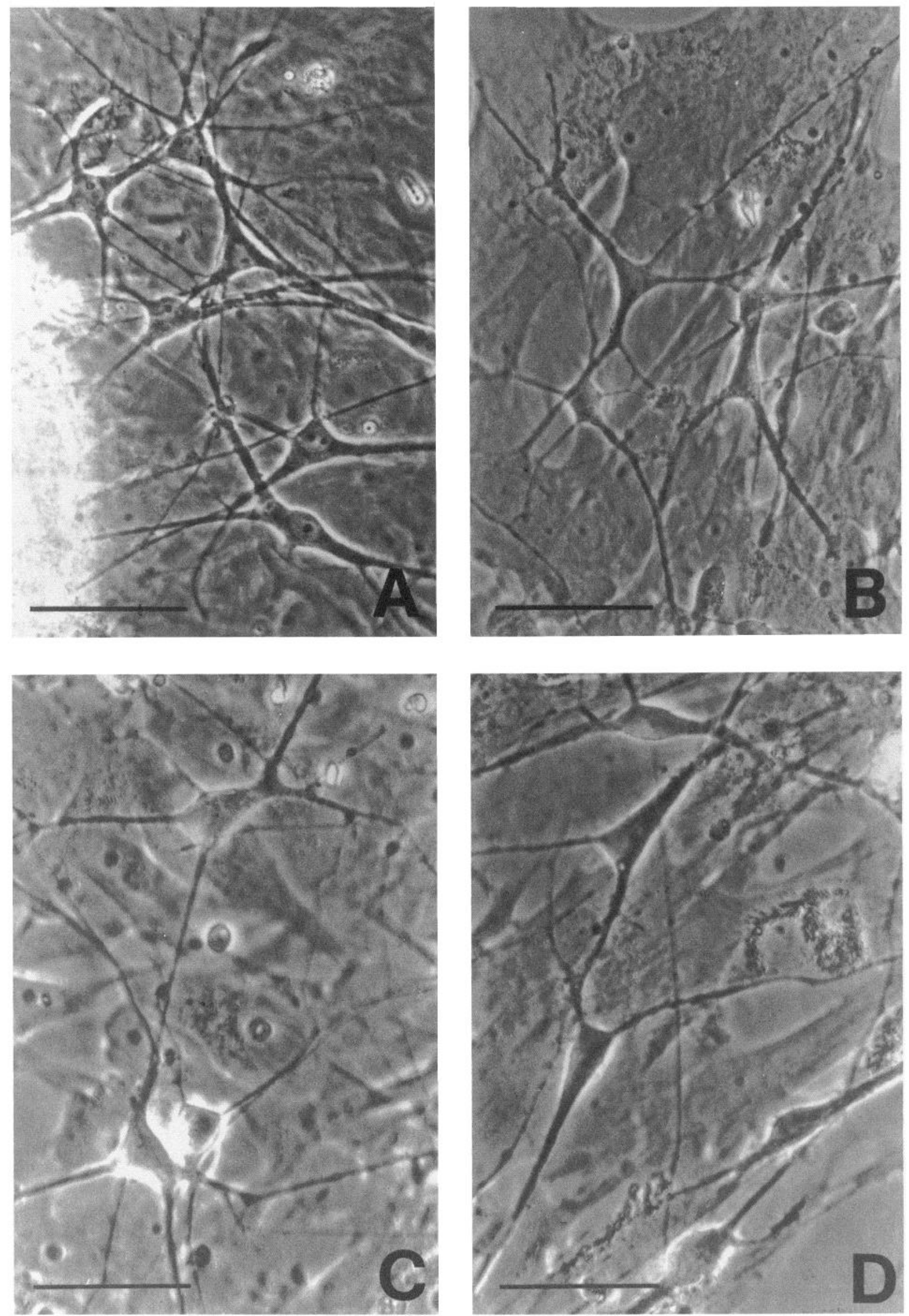
Table 1. Effects of serum concentration upon in vitro neurogenesis by adult HVc explants

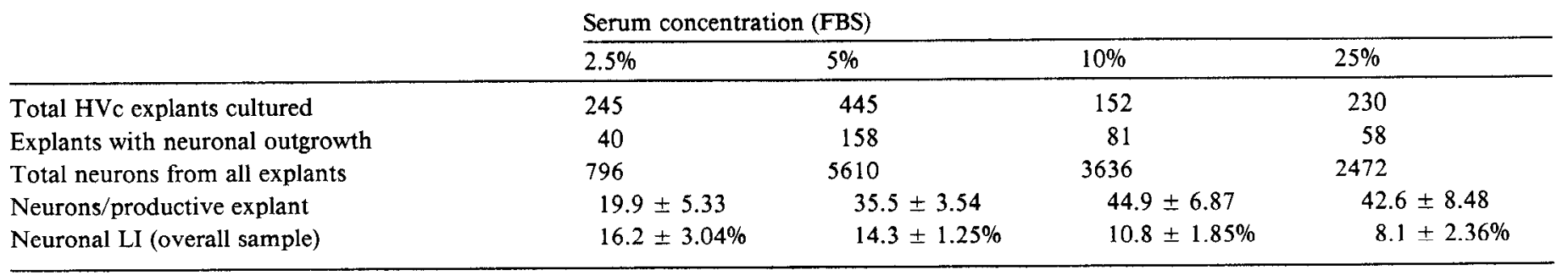

sociation with the labeling index of each explant, including the source bird, plate, serum concentration, and the time point of ${ }^{3} \mathrm{H}$-thymidine administration. Although the birds constituted an apparently homogeneous sample, possible differences in the neuronal labeling indices among individual birds of this outbred population were expected. In addition, since the explants derived from each bird were distributed among at least eight plates, differences in the labeling indices resulting from variability in the culture environment intrinsic to each plate were also considered. Our major hypotheses were that the neuronal labeling index would depend upon (as an inverse function) the ambient serum concentration and/or the time point of ${ }^{3} \mathrm{H}$-thymidine addition. To this end, a generalized linear model was used to determine whether time (1, $2,3,4$, and $5 \mathrm{~d}$ time points of ${ }^{3} \mathrm{H}$-thymidine addition) and serum concentration $(2.5 \%, 5 \%, 10 \%$, and $25 \% \mathrm{C}$-FBS) were associated with the neuronal labeling index, after controlling for the expected variability among individual birds, plates, and explants (Searle, 1987). We also considered whether the relationship between the neuronal labeling index and the serum concentration differed as a function of the time point of ${ }^{3} \mathrm{H}$-thymidine exposure. The use of this model is based upon the assumption of normally distributed data. Thus, the square root transformation was used to improve the normality in the distribution of neuronal labeling indices at each serum concentration.

Pairwise comparisons for time and serum concentration were tested separately, using the one-sided $t$ test with a Bonferroni adjustment to the significance level [a downward adjustment of the overall significance level, $\alpha$, by a factor of $\alpha(1 / \kappa)$, where $\kappa=$ number of comparison tests performed]. This was done in order to reduce the chance of falsely rejecting the null hypothesis, thereby compensating for the use of multiple comparisons within this data set. The Bonferroni method is applicable in this case given the unbalanced sample sizes and the few hypotheses being tested (Miller, 1981). Among the different serum concentrations, five comparisons were of primary interest: (1) $2.5 \%$ versus $5 \%$ FBS; (2) $5 \%$ versus $10 \%$; (3) $10 \%$ versus $25 \%$; (4) $5 \%$ versus $25 \%$; (5) $2.5 \%$ versus $25 \%$. A comparison was considered significant if the associated $p$ value was less than $p=0.01$, based upon a one-sided test of the null hypothesis, and an adjusted $p$ value of $\alpha / k=0.05 / 5$.

Kruskal-Wallis nonparametric one-way analysis of variance (ANOVA) was used to test for differences in the average number of neurons per explant as a function of serum concentration, over the range spanning 2.5-25\% C-FBS. This was done to detect any effects of serum concentration upon neuronal outgrowth (itself a function of migration efficacy, morphogenesis, and survival in vitro), which might in turn have differentially influenced the neuronal labeling index at each serum concentration. Post hoc pairwise comparisons were also tested using the nonparametric Wilcoxon rank-sum test, again with a Bonferroni adjustment of the significance levels to account for multiple comparisons.

In addition, in order to detect any correlation between each explant's neuronal labeling index with its overall neuronal outgrowth, Pearson's correlation coefficient was calculated individually at each serum concentration. This test was used to examine the relation between each explant's neuronal outgrowth with its percentage of ${ }^{3} \mathrm{H}$-thymidine-la- beled neurons, as distinct from the previously tested interaction between total neuronal outgrowth and serum level; the latter was tested independently using nonparametric ANOVA, as noted.

\section{Results}

Low serum culture of adult forebrain explants

Among the 1231 ventricular zone explants cultured in the experimental series, 337 (27.4\% overall) exhibited neuronal outgrowth (Table 1). Among the media compositions employed, neuronal outgrowth was observed in as little as $2.5 \%$ serum. No differences were noted in either the developmental schedules or morphologies (Fig. 1) of neurons migrating from explants raised in $25 \%$ serum, compared to those in $10 \%, 5 \%$, and $2.5 \%$ FBS. Under all of these conditions, explants of the adult canary HVc could be maintained for at least 2 weeks in vitro. No neuronal outgrowth, however, was observed in media containing $1.25 \%$ ( $n=61$ explants) or $0.625 \%$ serum $(n=35)$. This sharp threshold effect suggested the existence of one or more critical, survivallimiting serum factors, without which adult neuronal migration and outgrowth could not be supported in vitro.

\section{Neuronal outgrowth as a function of serum concentration}

Nonparametric one-way ANOVA was used to search for any effect of the serum concentration upon the median number of neurons per explant, over the range of $2.5-25 \%$ C-FBS (Table 1). This was done to detect any influence of serum upon neuronal outgrowth, which is itself a function of migration efficacy, morphogenesis, and survival in vitro. Our concern here was that should such an effect exist, it might differentially influence the neuronal LI at various serum concentrations. Over the range of $5-25 \%$ serum, no significant rclation was found between serum concentration and the extent of neuronal outgrowth. However, significantly lower neuronal counts were found in cultures raised in $2.5 \%$ C-FBS, relative to $5 \%$ and $10 \%$ FBS $(p=0.006$ and $p$ $=0.001$, respectively; sce Table 1$)$. This may reflect a deleterious effect of relative serum deprivation upon either neuronal migration or viability in these cultures. Thus, we cannot exclude the possibility that the percentage of labeled neurons in cultures raised in $2.5 \%$ C-FBS may have been differentially influenced by the low ambient serum concentration, relative to that of explants raised at higher serum concentrations.

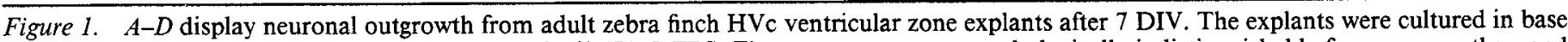

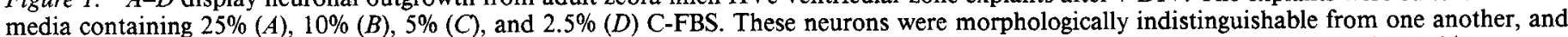

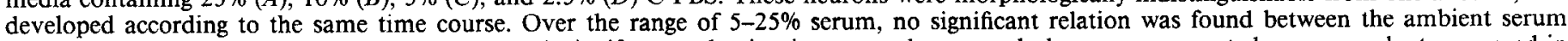

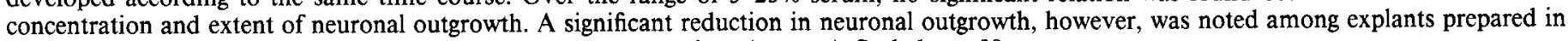
$2.5 \%$ C-FBS, relative to those raised in higher serum concentrations (see text). Scale bars, $50 \mu \mathrm{m}$. 

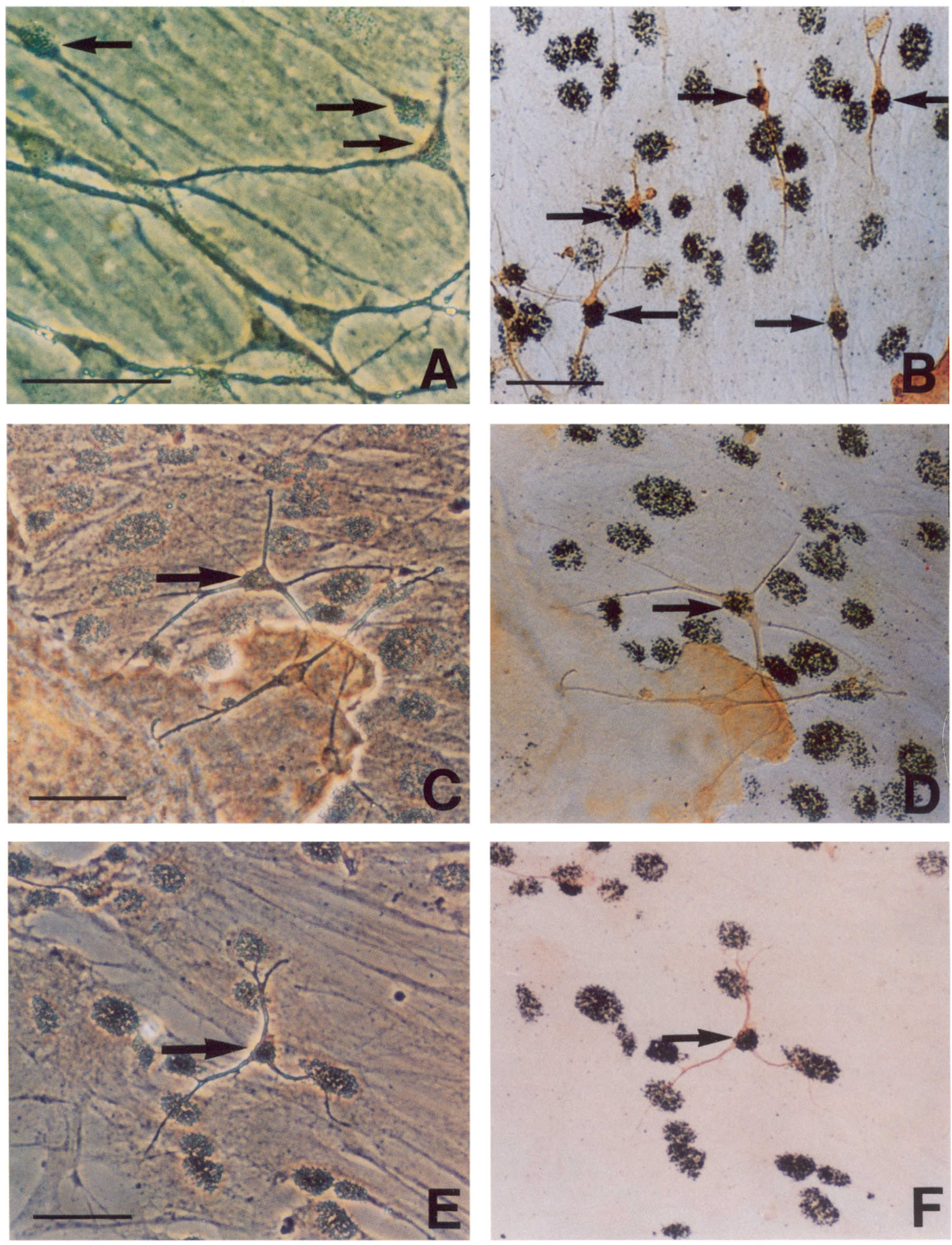


\section{Neuronal ${ }^{3} \mathrm{H}$-thymidine incorporation in low-serum media}

${ }^{3} \mathrm{H}$-thymidine-labeled neurons were observed at all of the serum concentrations tested (Table 1), but were most prevalent as serum concentration declined (Fig. 2). In order to quantify the effects of serum concentration and time in vitro upon in vitro neuronal mitogenesis, we determined the neuronal LI for each explant. This was defined as the number of ${ }^{3} \mathrm{H}$-thymidine-labeled, MAP-2-positive neurons found within each explant's cellular outgrowth, divided by the total number of neurons present in that outgrowth, expressed as a percentage. Using a general linear model to examine the data (see Materials and Methods), the neuronal LI was found to be significantly associated with the source bird $(p=0.001)$, serum concentration $(p=0.025)$, and time point of initial ${ }^{3} \mathrm{H}$-thymidine exposure $(p=0.006)$. The main effect of serum concentration upon the neuronal LI was inhibitory, resulting in a significant reduction in the percentage of ${ }^{3} \mathrm{H}$-thymidine-labeled neurons at higher serum concentrations $(F=3.1, p=0.025$; see Table 1). For instance, while $18.1 \pm 2.21 \%$ of neurons (mean $\pm \mathrm{SE}$ ) found in HVc cultures raised in 5\% C-FBS incorporated ${ }^{3} \mathrm{H}$-thymidine added after 1 DIV ( $n=158$ explants), only $8.0 \pm 2.69 \%$ of neurons raised in $25 \%$ C-FBS did so $(n=58)$.

Pairwise comparisons were also performed on the data (with Bonferroni adjustment to account for the use of multiple comparisons), with the LIs at each serum concentration pooled to include all five time points of ${ }^{3} \mathrm{H}$-thymidine addition (Fig. 3). The difference between the neuronal LIs of those explants raised in $5 \%$ and $25 \%$ C-FBS was highly significant $(p=0.0005$; Table 1 ), as was that between the $2.5 \%$ and $25 \%$ serum conditions ( $p$ $=0.01)$. Within this serum range, the mean neuronal LI of cultures raised in $5 \%$ serum was higher than that of cultures raised in $10 \%$ C-FBS $(p=0.02$; an adjusted $p<0.01$ was required for statistical significance at the overall $\alpha=0.05$ level, given the five separate serum comparisons performed within this data set). However, no significant differences were found between the mean neuronal LI of explants raised at the adjacent serum levels $2.5 \%$ and $5 \%$ C-FBS $(p=0.47)$, and $10 \%$ and $25 \%$ C-FBS $(p=0.09)$.

\section{Neuronal ${ }^{3} \mathrm{H}$-thymidine incorporation among high-outgrowth explants}

The mean number of neurons within each explant outgrowth was significantly lower in $2.5 \%$ C-FBS than in higher serum concentrations, as noted above. The relatively low number of neurons migrating from $\mathrm{HVc}$ explants in low serum appeared to be a function of decreasing substrate cell outgrowth under these serum conditions. Although neuronal morphology and developmental time course remained constant in low serum (Fig. 1), the expansion of substrate cell populations (ependymal and glial) was noticeably hampered, to the detriment of neuronal migration. Neurons thus frequently grouped at the border of

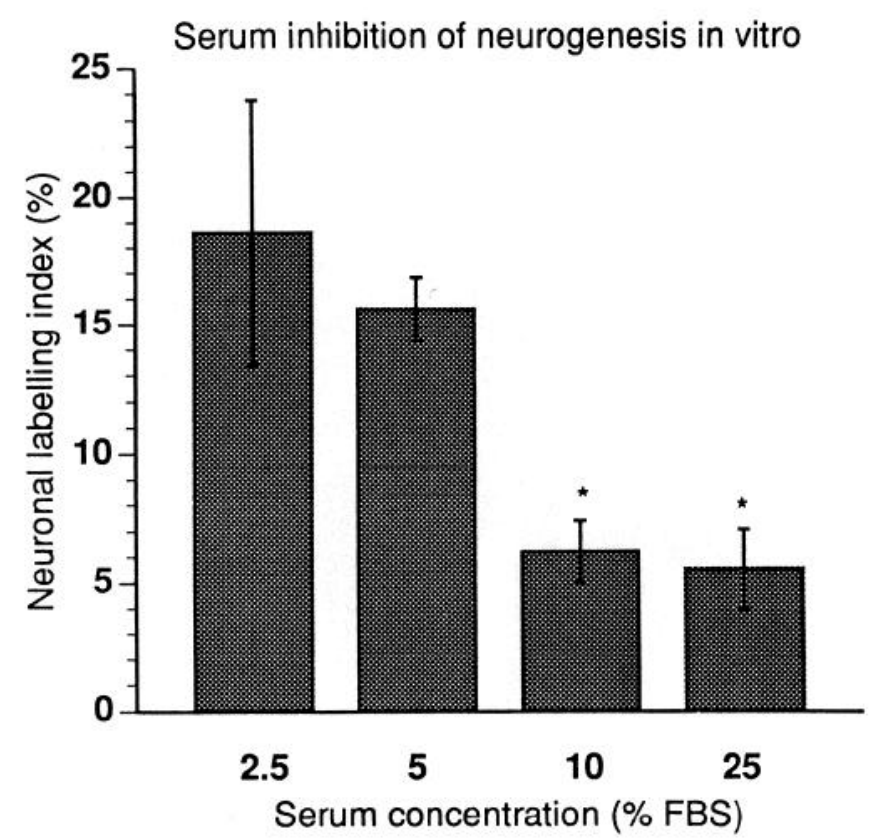

Figure 3. This graph plots the neuronal LI, defined as the mean percentage of labeled neurons per explant, as a function of serum concentration (FBS). The graph includes pooled data, derived from cultures to which ${ }^{3} \mathrm{H}$-thymidine was first added at time points ranging from 1 through 5 DIV. The data set upon which it is based includes only those explants that yielded $\geq 10$ neurons/outgrowth (see text). The neuronal LI of cultures raised in $2.5 \%$ or $5 \%$ serum was greater than that of cultures raised in higher serum concentrations (significance denoted by asterisks: $p<0.0001$ for both $5 \%$ vs. $10 \%$, and $5 \%$ vs. $25 \%$ ).

explants raised in $2.5 \%$ serum, seemingly unable to migrate farther. As a result, these explants yielded artifactually low total neuronal counts, since neurons within these cultures were not counted unless clearly distinct from their parent explants. In order to address this concern, we also analyzed the data to include only those explants with 10 neurons (Table 2). This manipulation had the effect of preferentially deleting from the sample those explants with deficient substrate cell outgrowth. As a result, total explant numbers were reduced by over a third (from 337 to 211 explants, or down $37 \%$ overall), while total neuronal numbers were minimally affected (dropping from 12,514 to 11,952 , a $4 \%$ decline). This reanalysis substantially normalized the data, and lowered its variance at each serum concentration, despite the lower sample sizes.

Using this restricted data set, the differences between neuronal LIs across serum concentrations were accentuated (Table 2; see also Fig. 3): Among neurons arising from explants with 10 neurons, $18.6 \pm 5.18 \%$ were ${ }^{3} \mathrm{H}$-thymidine labeled in $2.5 \% \mathrm{C}$-FBS $(n=697)$, versus $5.5 \pm 1.55 \%$ in $25 \%(n=2380, p=0.0128)$. This compares to the overall data set, in which $16.2 \pm 3.04 \%$

Figure 2. These images display the autoradiographed outgrowth of explants raised in 5\% C-FBS, and exposed to ${ }^{3} \mathrm{H}-$ thymidine after 1 DIV. All were fixed for autoradiography after 8 DIV. $A$ shows a group of both ${ }^{3} \mathrm{H}$-thymidine-labeled (arrows) and unlabeled neurons. This admixing of neurons generated in vitro with those already postmitotic was typical. $B-F$ were immunoperoxidase stained for MAP- 2 prior to autoradiography. $B$ reveals several ${ }^{3} \mathrm{H}$-thymidine-labeled, MAP-2-positive neurons (arrows) found migrating upon a layer of ciliated ependymal cells; most were radially oriented with respect to their parent ventricular zone explant. $C$ and $D$, and $E$ and $F$ show paired images, with the phase-contrast images of the left panel $(C$ and $E$ ) revealing cellular morphology, and the Nomarski images of the right panel $(D$ and $F)$ better displaying the concurrent silver grain deposition by ${ }^{3} \mathrm{H}$-thymidine and neuronal MAP-2 immunostaining. These ${ }^{3} \mathrm{H}$-thymidine-labeled, MAP-2-positive cells underwent DNA replication, and presumably mitogenesis in vitro, with neuronal maturation and antigenic expression occurring during the following week. Scale bars, $25 \mu \mathrm{m}$. 


\section{Adult neurogenesis as a function of time in vitro}

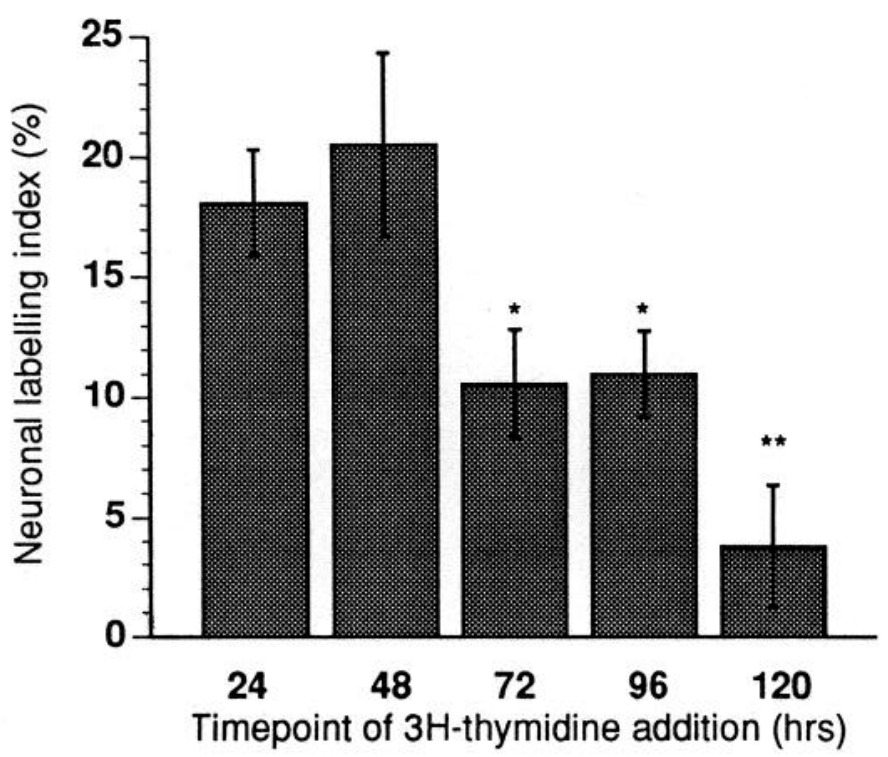

Figure 4. This graph displays the neuronal LI as a function of the initial time point of ${ }^{3} \mathrm{H}$-thymidine exposure, among cultures raised in $5 \%$ serum. This concentration was used as an arbitrary standard at which to evaluate the persistence of neurogenesis in vitro. The neuronal LI was highest in those cultures to which ${ }^{3} \mathrm{H}$-thymidine was added after 1 or 2 DIV ( 24 or $48 \mathrm{hr}$ ), relative to those first exposed to ${ }^{3} \mathrm{H}$-thymidine after 3 or 4 DIV ( 72 or $96 \mathrm{hr}$; significant differences denoted by asterisks). In addition, the neuronal LI of cultures to which ${ }^{3} \mathrm{H}$-thymidine was added after 5 DIV $(120 \mathrm{hr})$ was still lower than that of the other time points, indicating a further diminution in neuroblastic ${ }^{3} \mathrm{H}$-thymidine incorporation with time in culture. The data may suggest the sequential division of individual precursor cells, with more labeled progeny resulting from earlier tracer addition to the cultures.

of neurons in $2.5 \% \mathrm{C}$-FBS $(n=796)$, and $8.1 \pm 2.36 \%$ in $25 \%$ ( $n=2472)$, were labeled ( $p=0.01$ ). Again considering only neurons arising from explants with 10 neurons, the difference between the neuronal LIs in 5\% C-FBS (15.6 $\pm 1.25 \%, n=$ $5355)$ and $10 \%(6.2 \pm 1.20 \%, n=3520)$ was significant $(p<$ $0.0001)$, although the respective differences between $2.5 \%$ and $5 \%(p=0.47)$, and $10 \%$ and $25 \%(p=0.45)$ were not.

\section{Glial and ependymal ${ }^{3} \mathrm{H}$-thymidine incorporation in low-serum media}

The cellular outgrowth of all explants exposed to ${ }^{3} \mathrm{H}$-thymidine in vitro also revealed heavy labeling of both glial and ependymal substrate cells. In vitro mitogenesis persisted among these cell types at all serum concentrations. However, the LIs of the sub- strate cell types were not quantified, as we made no attempt to determine the effects of serum concentration upon glial and ependymal proliferation rates.

\section{Methodological controls}

Among the 71 explants exposed to ${ }^{3} \mathrm{H}$-thymidine beginning 7 DIV and fixed $1 \mathrm{~d}$ later, 25 explants produced neuronal outgrowth ( 11 of 28 explants in $5 \%$ C-FBS and 14 of 43 in $25 \%$ ). Within these explant outgrowths, 740 morphologically defined neurons were counted in either the $5 \%$ or $25 \%$ serum conditions. Of these, three ${ }^{3} \mathrm{H}$-thymidine-labeled neurons $(0.4 \%)$ were noted ( 1 of 192 in $5 \%$ and 2 of 548 in $25 \%$ ), while the remaining 737 $(99.6 \%)$ were unlabeled. Among the unlabeled neurons, little if any silver grain deposition was noted. These results suggest that unscheduled ${ }^{3} \mathrm{H}$-thymidine uptake, as defined autoradiographically, was either rare or nonexistent in these cultures.

\section{Persistence of in vitro neurogenesis in low serum concentrations}

${ }^{3} \mathrm{H}$-thymidine was added to these cultures at varying time points in vitro, including $1,2,3,4$, and $5 \mathrm{~d}$ after explantation: in all cases, the cultures were fixed for autoradiography 7-8 d after their respective ${ }^{3} \mathrm{H}$-thymidine additions. At all serum concentrations tested, neuronal ${ }^{3} \mathrm{H}$-thymidine labeling was greatest in cultures to which ${ }^{3} \mathrm{H}$-thymidine was added after 1 or 2 DIV. We used 5\% C-FBS as a standard serum level for examining the effects of time in vitro upon neurogenesis, since this was the lowest serum concentration tested at which total neuronal numbers were not significantly different from those found in highserum $(25 \%)$ cultures (Table 1). At this 5\% serum level, the neuronal LIs for the 1 and $2 \mathrm{~d}$ time points were $18.1 \pm 2.21 \%$ ( $n=68$ explants) and $20.5 \pm 3.82 \%(n=14)$, respectively (Fig. 4). Although these values did not significantly differ from one another $(p=0.17)$, both were higher than those obtained from cultures first exposed to ${ }^{3} \mathrm{H}$-thymidine after 3 DIV (10.6 \pm $2.26 \%, n=38 ; p=0.006$ for the comparison between 2 vs. 3 DIV isotope additions). No significant difference was noted between the neuronal LI of cultures exposed after $3 \mathrm{~d}$ versus their $4 \mathrm{~d}$ counterparts $(11.0 \pm 1.82 \%, n=25)$. The LI of cultures first given ${ }^{3} \mathrm{H}$-thymidine after 5 DIV $(3.8 \pm 2.55 \%, n=13)$, however, was significantly lower than that of cultures exposed after $4 \mathrm{~d}(p=0.004)$, despite evidence of some persistent neurogenesis even after 5 DIV (Fig. 4).

\section{Neuronal ${ }^{3} \mathrm{H}$-thymidine labeling as a function of neuronal outgrowth}

We also sought to determine whether the percentage of labeled neurons found in each explant outgrowth was dependent upon the overall number of neurons originating from that explant. Pearson's correlation coefficient was thus used to estimate the

Table 2. Effects of serum concentration upon neurogenesis by explants yielding $\geq 10$ neurons

\begin{tabular}{lccrr} 
& \multicolumn{2}{l}{ Serum concentration (FBS) } & \multicolumn{1}{c}{$10 \%$} & $25 \%$ \\
\cline { 2 - 4 } & $2.5 \%$ & $5 \%$ & 152 & 230 \\
Total HVc explants cultured (from Table 1) & 245 & 445 & 55 & 34 \\
Explants with $\geq 10$ neurons & 17 & 105 & 3520 & 2380 \\
Total neurons from explants with $\geq 10$ neurons & 697 & 5355 & $63.9 \pm 9.14$ & $69.9 \pm 12.74$ \\
Neurons/explant among those with $\geq 10$ neurons & $41.0 \pm 11.03$ & $51.4 \pm 4.63$ & $6.2 \pm 1.20 \%$ & $5.5 \pm 1.55 \%$
\end{tabular}


correlation between these variables, and was calculated separately for each serum concentration. No significant correlation was found between the number of neurons per explant and the corresponding neuronal LIs, at any of the four serum concentrations tested $(2.5 \% \mathrm{C}$-FBS, $r=-0.12 ; 5 \% \mathrm{C}$-FBS, $r=+0.06$; $10 \% \mathrm{C}$-FBS, $r=-0.25 ; 25 \%$ C-FBS, $r=-0.16$. All $p$ values $>0.03$, with $p=0.006$ required for an overall significance level of $\alpha=0.05$ given four independent, two-sided comparisons). In addition, a set of scatter plots were produced, which plotted the neuronal LI against the number of neurons per explant, at each of the four serum concentrations studied. These plots failed to reveal any relationship, linear or nonlinear, between the neuronal LI and degree of neuronal outgrowth. Thus, the percentage of its neurons generated by a given explant in vitro did not depend upon the number of neurons arising from that explant, but rather was a direct function of the serum concentration to which it was cxposcd.

\section{Discussion}

Among these explant cultures derived from neurogenic regions of the adult songbird forebrain, in vitro ${ }^{3} \mathrm{H}$-thymidine uptake by neuronal progenitor cells could be demonstrated at least $5 \mathrm{~d}$ after explanation. These results represent an unusual example of in vitro neurogenesis, with neuronal production by cultured adult forebrain ventricular zone. As such, this preparation provides an ex vivo means by which to analyze both the humoral controls upon adult neurogenesis, and the role of regional astrocytes and ependymal cells in regulating neuronal mitogenesis in the adult avian forebrain. In this regard, although in vitro neurogenesis occurred over a wide range of serum concentrations, it was most frequent in cultures raised in low serum. Thus, fetal serum may contain factors capable of arresting the division of the adult neuronal progenitor cells, either directly, or through agents released by serum-stimulated glial or ependymal cells.

\section{Serum-related suppression of neuronal ${ }^{3} H$-thymidine labeling}

In vitro neuronal mitogenesis fell significantly in adult $\mathrm{HVc}$ cultures raised in relatively high concentrations of serum, and was least common in cultures raised in 25\% FBS (Fig. 3). Many, if not most, of the premitotic neuronal precursors placed in highserum culture appeared to become mitotically quiescent. These cells might have undergone an unscheduled terminal differentiation-most likely, but not necessarily, into neurons-or may have instead remained within their parent explants in a viable, but mitotically inactive state. Alternatively, undetected neurogenesis may have occurred within these explants, as newly generated neurons may have failed to migrate from the explanted ventricular zone, or might simply have become nonviable in the high-serum environment. Since the total number of neurons emigrating from each explant and surviving to be counted was not diminished by high-serum culture (Table 1), these latter possibilities would seem unlikely. Rather, the results suggest that under the high-serum incubation conditions employed, mitotic activity within the adult $\mathrm{HVc}$ neuronal precursor pool was inhibited, even while postmitotic neuronal migration and maturation proceeded apace. These results are consistent with those of our previous study (Goldman, 1990), in which little ${ }^{3} \mathrm{H}$ thymidine incorporation (from $4 \mathrm{hr}$ in vitro until fixation $7 \mathrm{~d}$ later) was noted among neurons arising from a sample of 45 adult canary $\mathrm{HVc}$ explants, all of which were raised in $25 \%$ serum $(3: 2$, fetal bovine : chicken). Interestingly, these earlier canary-derived cultures contained a fraction of avian serum (adult chicken), which might have been more effective at suppressing neuronal mitogenesis in this system than the mammalian fetal sera used in our present study (S. A. Goldman and A. Zaremba, unpublished observations).

\section{Cessation of neurogenesis as a function of duration in culture}

Even using low-serum culture conditions, neuronal ${ }^{3} \mathrm{H}$-thymidine incorporation fell rapidly after the fourth day in vitro, such that explants first exposed to ${ }^{3} \mathrm{H}$-thymidine after 5 DIV yielded few labeled neurons (Fig. 4). One might suppose that since the culture medium was never changed during the first week in vitro, factors released by the expanding glial and ependymal cell populations may have accumulated, and ultimately acted to suppress mitogenesis among the cocultured neuronal precursors. If so, then one would predict that frequent replenishment of the cultures with fresh, unconditioned media would permit the adultderived precursor population to remain mitotically active for longer periods of time in vitro.

\section{Astrocytic conditioning of media}

The serum-dependent suppression of in vitro neuronal mitogenesis may be a function of glial-derived factors, whose production may be induced by serum-borne agents. For instance, high-serum concentrations might stimulate glial proliferation and/or maturation, resulting in the induction of glial agents that would then act upon the ventricular zone precursor cells as antimitotic or prodifferentiative factors. Indeed, such astrocytic inhibition of in vitro neurogenesis has already been described in cultures of postnatal cerebellar granule cells (Gao and Hatten, 1990). In our adult HVc cultures, serum might therefore inhibit $\mathrm{HVc}$ neuronal mitogenesis either in a directly suppressive manner, or by supporting cocultured glial populations. Our present data do not yet allow us to distinguish between these possibilities.

\section{Kinetics of neuronal generation}

The neuronal LI did not differ between cultures first exposed to ${ }^{3} \mathrm{H}$-thymidine on the first or second days in vitro, but declined significantly in cultures first exposed to ${ }^{3} \mathrm{H}$-thymidine on the third and fourth days in culture, with another significant decline occurring on day 5 in vitro (Fig. 4). If neuronal precursor mitosis were to continue beyond more than one division in vitro, then one would expect the number of labeled neurons to increase as ${ }^{3} \mathrm{H}$-thymidine exposures were initiated earlier. The neuronal LI would increase with longer exposures to ${ }^{3} \mathrm{H}$-thymidine, as the pool of unlabeled, postmitotic neurons became diluted by the addition of labeled neurons generated in vitro. Since the respective fractions of premitotic and postmitotic progeny of these adult-derived precursors are unknown, the present data do not allow one to determine accurately the cell cycle kinetics of these cells: it remains to be determined, in vivo as well as in vitro, whether the neuronal stem cells divide with both daughter cells retaining the capacity for subsequent mitosis prior to neuronal differentiation, or whether mitotic potential is retained by only one of the daughter neuroblasts. If one assumes that daughter cell production is asymmetric, with precursor cell division yielding one mitotically competent precursor cell and one postmitotic neuron, then our present data might suggest a cell cycle time of $48 \mathrm{hr}$ for the ventricular zone precursor population in vitro. In addition, under the culture conditions employed, it appears that the precursor cells underwent no more than two divisions in vitro. 


\section{Validation of neuronal identity by immunolocalization of $M A P-2$}

Culture outgrowths were immunostained for the neuron-selective antigen MAP-2 (Bernhardt and Matus, 1985; Caceres et al., 1986), in order to confirm the identity of ${ }^{3} \mathrm{H}$-thymidine-labeled neurons, and also to ease in the quantification of these cells (Fig. 2 ). This was especially helpful in cultures raised in $2.5 \%$ serum, at which point substrate cells tended to spread less, and assumed fusiform morphologies that frequently were indistinguishable from those of young bipolar neurons (Fig. 1D). However, the intensity of the MAP-2 staining varied as a function of the age of each cell. Neurons that had migrated farthest from their parent explants were generally the most heavily neuritic and morphologically mature, and were highly immunoreactive for MAP2. However, those migratory neurons closest to or still leaving the explant, which were typically bipolar and morphologically immature, were variably immunoreactive for MAP-2. It is likely that these immature neurons had been generated only in the few days before culture fixation. As a result of their light MAP-2 immunostaining, these cells were consistently undercounted in our sample, at least with respect to independent estimates obtained using morphological criteria alone. Nevertheless, ${ }^{3} \mathrm{H}$-thymidine-labeled cells of neuronal morphology that displayed no evidence of any MAP-2 staining were excluded from our sample. This undercounting may have resulted in reduced estimates of neuronal production in culture, since of each explant's complement of ncurons, those neurons generated in vitro would be the least mature, and hence the least immunoreactive for MAP-2. Longer survival times in culture, before fixation and immunocytochemical staining, might have provided even more precise estimates of the fraction of neurons generated in vitro than those that we obtained in the present study.

\section{${ }^{3} \mathrm{H}$-thymidine uptake as a marker of cell division}

We have used ${ }^{3} \mathrm{H}$-thymidine incorporation as inferential evidence for precursor cell mitogenesis in vitro. Although we have not directly observed neuroblastic division in culture, this is not surprising in this system, since precursor cell mitosis would be expected to occur within the confines of the ventricular zone explant. Nevertheless, one must consider other possible sources of ${ }^{3} \mathrm{H}$-thymidine incorporation in vitro, such as mitochondrial uptake and DNA repair. It is unlikely that mitochondrial ${ }^{3} \mathrm{H}$ thymidine uptake was a significant source of spurious neuronal labeling, since the ${ }^{3} \mathrm{H}$-thymidine-labeled neuronal nuclei, like their glial and ependymal counterparts, were accompanied by little if any cytoplasmic labeling. This is in accordance with previous estimates that mitochondrial DNA constitutes less than $0.15 \%$ of total cellular DNA (Attardi, 1985), rendering the autoradiographic contribution of mitochondrial ${ }^{3} \mathrm{H}$-thymidine uptake to total cellular labeling relatively slight.

Another possible source of unscheduled (outside of S-phase) DNA synthesis and ${ }^{3} \mathrm{H}$-thymidine incorporation is DN $\Lambda$ repair (Strauss, 1974; Haseltine, 1983; Sancar and Sancar, 1988). Although the rate of DNA turnover in stable, postmitotic cells is so low as to be autoradiographically negligible (Mares and Lodin, 1974), one must consider the possibility that either the tritium exposure or low-serum growth conditions might have activated DNA repair in our cultures. Indeed, a very small number of ${ }^{3} \mathrm{H}$-thymidine-labeled neurons $(0.4 \%)$ were found in those control cultures exposed to ${ }^{3} \mathrm{H}$-thymidine after 7 DIV and fixed $1 \mathrm{~d}$ later. However, were DNA repair active in these cultures, then one would expect cellular ${ }^{3} \mathrm{H}$-thymidine incorporation to have been ubiquitous, rather than limited to the small percentage of heavily labeled cells that we observed. By the same reasoning, one might expect a stochastically determined, normally distributed intensity of labeling among cells undergoing DNA repair, rather than the uniform degree of silver grain deposition noted over labeled neurons in these cultures. In addition, one would predict a difference in labeling intensity between proliferative glia and their cocultured neurons, were the latter incorporating ${ }^{3} \mathrm{H}$-thymidine solely as a result of DNA repair, since the rate of ${ }^{3} \mathrm{H}$-thymidine incorporation by damaged cells is substantially less than that of their dividing counterparts (Evans et al., 1970; Friedberg, 1985). Instead, we observed that the mean grain count of ${ }^{3} \mathrm{H}$-thymidine-exposed neurons in our low-serum cultures was indistinguishable from that of concurrently exposed, proliferating glial and ependymal cells, whether in high- or in low-serum media (Goldman and Zaremba, unpublished observations). Finally, one might predict that if neuronal ${ }^{3} \mathrm{H}$-thymidine incorporation were a result of tritium-induced DNA damage, then the LI would bear no necessary relation to serum concentration. Instcad, we observed a suppressive effect of serum upon the neuronal LI. Thus, it is unlikely that the few labeled neurons noted in our control cultures exposed to ${ }^{3} \mathrm{H}$-thymidine after $7 \mathrm{DIV}$ and fixed $1 \mathrm{~d}$ later were undergoing either DNA repair, or otherwise unscheduled ${ }^{3} \mathrm{H}$-thymidine uptake. These cells might have been the progeny of late-dividing precursors, and may have been completing S-phase at the time of ${ }^{3} \mathrm{H}$-thymidine addition, with neuronal maturation to a bipolar morphology by the time of fixation $24 \mathrm{hr}$ later. Alternatively, they might constitute an index of operational false positivity in our morphological determinations of neuronal numbers (these cells, unlike the experimental series as a whole, were not stained for MAP-2 prior to autoradiography). In either case, the rarity of these cells suggests that the incidence of spurious neuronal ${ }^{3} \mathrm{H}$-thymidine labeling in these cultures was quantitatively insignificant.

\section{In vivo correlates}

On the basis of these results, one might postulate that in the live adult songbird forebrain, fluctuations in neuronal production and turnover may be governed as in vitro, by agents capable of suppressing neuronal mitogenesis. As in culture, these agents might be either serum-borne, or locally derived from serumstimulated glial and/or ependymal cells: first, brain-derived factors could reach the ventricular zone from the cerebrospinal fluid (CSF), as could systematically produced agents, via choroid plexus release into the CSF. Alternatively, if ependymal or astrocytic in origin, they might gain access to the ventricular zone through local parenchymal release and interstitial diffusion. Indeed, given the regional heterogeneity of the adult songbird ventricular zone, with many focally restricted patches of mitotic neuroepithelium dispersed about an otherwise non-neurogenic ependymal layer (Alvarcz-Buyulla ct al., 1990), the determination of neuronal mitogenesis might be expected to be under some degree of local control. Whatever their cellular source, however, these factors must ultimately act upon the ventricular zone epithelium, through one of several alternative means. First, these apparent neuroblastic antimitogens might act by directly promoting the departure of phenotypically committed ventricular zone precursor cells from the cell cycle, with secondary neuronal commitment and phenotypic differentiation. Alternatively, these agents might function to promote the terminal 
differentiation of similarly lineage-restricted but still premitotic neuroblasts, with exit from the cell cycle a necessary but secondary consequence of neuronal differentiation. Finally, these agents might act by influencing the fate of ventricular zone daughter cells, by directly determining their phenotypic commitment without affecting the underlying mitotic rate of their parent precursor cells. This latter possibility has been made feasible by our recent demonstration, through retroviral lineage analysis, that the adult $\mathrm{HVc}$ ventricular zone precursor cell is pluripotential, generating both neurons and non-neuronal siblings in vitro (Goldman and Mikawa, 1992). The present data thus suggest several strategies by which close control of adult neurogenesis might be accomplished, all sharing as their principal feature the active suppression of neuronal mitogenesis by otherwise tonically active ventricular zone precursor cells.

\section{References}

Alvarez-Buyulla A, Nottebohm F (1988) Migration of young ncurons in adult avian brain. Nature 335:353-354.

Alvarez-Buyulla A, Theelan M, Nottebohm F (1990) Proliferation hot spots in adult avian ventricular zone reveal radial cell division. Neuron 5:101-109.

Anderson M, Waxman S (1985) Neurogenesis in tissue cultures of adult teleost spinal cord. Dev Brain Res 20:203-212.

Attardi G (1985) Animal mitochondrial DNA: an extreme example of genetic economy. Intl Rev Cytol 93:93-145.

Banker G, Cowan M (1977) Rat hippocampal neurons in dispersed cell culture. Brain Res 126:397-425.

Barakat I, Labourdette G, Sensenbrenner M (1983) Inhibitory effects of fetal calf serum on proliferation of chick neuroblasts in culture. Dev Neurosci 6:169-183.

Barakat I, Courageot J, Devilliers G, Sensenbrenner M (1984) Effects of chick brain extract on the proliferation of chick neuroblasts cultured in media supplemented with low and high serum concentrations. Neurochem Res 9:263-272.

Bernhardt R, Matus A (1985) Differences in the developmental patterns of three microtubule associated proteins in the rat cerebellum. J Neurosci 5:977-991.

Bottenstein J, Sato G (1979) Growth of a rat neuroblastoma cell line in serum-free supplemented medium. Proc Natl Acad Sci USA 76: 514-517.

Caceres A, Banker G, Binder L (1986) Immunocytochemical localization of tubulin and MAP-2 during the development of hippocampal neurons in culture. J Neurosci 6:714-722.

Calof A, Chikaraishi D (1989) Analysis of neurogenesis in a mammalian neuroepithelium: proliferation and differentiation of an olfactory neuron precursor in vitro. Neuron 3:115-127.

Cattaneo E, McKay R (1990) Proliferation and differentiation of neuronal stem cells regulated by nerve growth factor. Nature 347:762765.

Evans R, Djordjevic B, Perez A (1970) Temperature dependence of thymidine uptake and stability of thymidine incorporated during unscheduled DNA synthesis in irradiated and unirradiated HeLa cells. Int J Radiol Biol 18:277-280.

Federoff S, Krukoff T, Fisher K (1982) The development of chick spinal cord in tissue culture: neuronal precursor cells in culture. In Vitro 18:183-194.
Fisher I, Kosik K, Sapirstein V (1987) Heterogeneity of microtubuleassociated protein (MAP2) in vertebrate brains. Brain Res 436:3948.

Friedberg E (1985) DNA repair. San Francisco: Freeman.

Gao W, Hatten M (1990) Granule cell neurogenesis in vitro. Soc Neurosci Abstr 16:174.

Gensburger C, Labourdette G, Sensenbrenner M (1987) Brain bFGF stimulates the proliferation of rat neuronal precursor cells in vitro. FEBS Lett 217:1-5.

Goldman S (1983) Neuronal production, migration and differentiation in the adult avian brain, in vivo and in vitro. $\mathrm{PhD}$ thesis, The Rockefeller University, New York.

Goldman S (1990) Neuronal development and migration in explant cultures of the adult canary forebrain. J Neurosci 10:2931-2939.

Goldman S, Clarke W (1989) In vitro antigenic and ultrastructural characterization of neuroblasts derived from a neurogenic region of the adult canary brain. Soc Neurosci Abstr 15:962.

Goldman S, Mikawa T (1992) Serum-dependent in vitro neurogenesis by multipotential precursor cells of the adult avian brain. Neurology 42(Suppl), in press.

Goldman S, Nottebohm F (1982) Ependymal neurogenesis in adult female canaries. Soc Neurosci Abstr 8:140.

Goldman S, Nottcbohm F (1983) Neuronal production, migration and differentiation in a vocal control nucleus of the adult female canary brain. Proc Natl Acad Sci USA 80:2390-2394.

Goldman S, Zaremba A (1991) In vitro neurogenesis by ventricular zone explants of the adult songbird forebrain. Soc Neurosci Abstr 17: 30.

Haseltine W (1983) Ultraviolet light repair and mutagenesis revisited. Cell 33:13-17.

Kriegstein A, Dichter M (1984) Neuron generation in dissociated cell cultures from fetal rat cerebal cortex. Brain Res 295:184-189.

Lillien L, Sendtner M, Rohrer H, Hughes S, Raff M (1988) Type-2 astrocyte development in rat brain cultures is initiated by a CNTFlike protein produced by type-1 astrocytes. Neuron 1:485-494.

Mares V, Lodin Z (1974) An autoradiographic study of DNA synthesis in adolescent and adult mousc forcbrain. Brain Res 76:557-561.

Mattson M, Guthrie P, Hayes B, Kater S (1989) Roles for mitotic history in the generation and degeneration of hippocampal neuroarchitecture. J Neurosci 9:1223-1232.

Miller J (1981) Simultaneous statistical inference, 2d ed. New York: Springer.

Murphy M, Drago J, Bartlett PF (1990) Fibroblast growth factor stimulates the proliferation and differentiation of neural precursor cells in vitro. J Neurosci Res 25:463-475.

Paton J, Nottebohm F (1984) Neurons born in adult brain are recruited into functional circuits. Science 225:1046-1048.

Ronnett G, Hester L, Nye J, Connors K, Snyder S (1990) Human cortical neuronal cell line: establishment from a patient with unilateral megalencephaly. Science 248:603-605.

Sancar A, Sancar G (1988) DNA repair cnzymes. Annu Rev Biochem 57:29-67.

Searle SR (1987) Linear models for unbalanced data. New York: Wiley.

Sensenbrenner M, Wittendorp E, Barakat I, Rechenmann R (1980) Autoradiographic study of proliferating brain cells in culture. Dev Biol 75:268-277.

Strauss B (1974) Repair of DNA in mammalian cells. Life Sci 15: 1865-1893.

Temple S (1989) Division and differentiation of isolated CNS blas cells in microculture. Nature $34: 471-473$. 